\title{
Household Preferences and Willingness to Pay for Waste Management Services in Rural Nigeria
}

\author{
Richardson Kojo Edeme \\ Department of Economics, University of Nigeria, Nsukka \\ Email(s): richard.edeme@unn.edu.ng; kojodynamics@yahoo.com \\ Nelson C. Nkalu (corresponding author) \\ Department of Economics, University of Nigeria, Nsukka \\ E-Mail(s): nelson.nkalu@unn.edu.ng; nkaluconnection@gmail.com
}

\begin{abstract}
Safe and clean environment is an essential requirement for maintaining life on earth and creating human friendly environment is one of the most important issues in the world today. The concern of this paper is to examine household preference and willingness to pay for waste management services. The population of the study is made up of the households in the Nsukka urban where simple random sampling techniques was employed to select 25 households from each of the six town in Nsukka urban, employing binary modelling using probit model to estimate the impact of both cultural and demographic factors and economic factors on household willingness to pay for waste management service. The result revealed that demographic factors such as age, household size and education have great influence on household willingness to demand for waste management in Nsukka urban area. Also, economic factors such, income level of the households, awareness of the household about the environment, impact of waste management service and cost of waste management service has positive significant impact on household willingness to pay for waste management services.
\end{abstract}

Keywords: Household, waste management services, binary model, probit model

\section{Introduction}

Waste is directly linked to human development, both technologically and socially. The composition of different wastes has varied over time and location, with industrial development and innovation being directly linked to waste materials. Waste management agencies have placed an increasing focus on reducing waste so that there is less to cope with. Attempts have been made by scholars, researchers, consultants and government to determine the actual amount of waste being generated in Nigeria in general (Agbola, 2001). In a survey carried out by (CASSAD, 1998) on waste generation in Nigeria. The study shows that the volume of wastes generated by all the states increased over the period between 1994 and 1996. It was estimated that by the year 2010, Nigeria will generate about 3.53 million tonnes of solid waste, based on a per capita solid waste generation of 20kg per year (Agbola, 2001). Nigerian urban areas have been said to be some of the dirtiest, the most unsanitized and the least aesthetically pleasing in the world (Alabi, 2004).

Attempts have been made by researchers to determine the actual amount of waste being generated in Nigeria (Agbola, 2001). In a survey carried out by (CASSAD, 1998) on waste generation in Nigeria, it was found that the volume of wastes generated by all the states increased between 1994 and 1996. It was estimated that by the year 2010, Nigeria will generate about 3.53 million tonnes of solid waste, based on a per capita solid waste generation of $20 \mathrm{~kg}$ per year (Agbola, 2001). Nigerian urban areas have been said to be some of the dirtiest, the most unsanitized and the least aesthetically pleasing in the world (Alabi, 2004). About 75 percent of solid waste collected in most Nigerian urban cities is disposed in open. This method which is rampant is not hygienic as it marginalizes the environment as a result of the negative externalities it generates (Adinnu 1994).

Safe and clean environment is an essential requirement for maintaining life on earth and creating human friendly environment is one of the most important issues in the world today (Khtak and Amin 2013). To meet the needs of rapidly growing population, it is obvious that production has to be increased by at least the population growth rate 
which leads to waste production that is beyond the absorptive capacity of the environment due to the hygienic problems as a result of the negative externalities it generates (Tarfasa, 2007, Subha, Ghani et al., 2014). The changing economic trends and rapid urbanization also complicate solid waste management in developing countries. Consequently, solid waste is not only increasing in quantity but also changing in composition from less organic to more paper, packing wastes, plastics, glass, metal wastes among other types, a fact leading to the low collection rates (Bartone\& Bernstein, 1993; Yusuf, Ojo, et al, 2007). Agreeing with this assertion, (CASSAD, 1998), stated that the decomposition of wastes on open dumping grounds emit intolerable smells and attract potential diseases. Wastes that are not well managed can affect the environment in terms of the contamination of the atmosphere, soil and water. This can cause severe problems for humans and animals population. It can also affect human health in particular by causing convulsion, dermatitis, irritation of nose/throat, anaemia, skin burns, chest pains, blood disorders, stomach aches, vomiting diarrhoea and lung cancer which may lead to death (Alabi, 2004). The social effect where flood which has resulted in loss of lives and properties worth millions of naira. Population growth, urbanization and greater exploitation of resources resulted in an increasing demand for environmental management. Particularly in developing countries urban areas, the people are facing sever challenges due to lack of healthy urban environment (Khtak \& Amin 2013).

Inadequate urban waste management is one of the major drivers to the degrading of environment quality in urban areas (UNPDDESA, 2005, Khattak, Khan et al., 2009, Wilson and Velis, 2014). This solid waste problem is due to high waste generation, inadequate waste collection, and poor disposal habits by the households/individuals, which is as a result of lack of appropriate planning, inadequate governance, resource constraint and ineffective management solid waste is a major source of concern in many rapidly growing cities in developing countries. According to UNEP (2004), solid waste generation has become an increasing environmental and public health problem everywhere in the world, particularly in developing countries. The fast expansion of urban agricultural and industrial activities stimulated by rapid population growth has produced vast amounts of solid and liquid wastes that pollute the environment and destroy resources.

In the past, most attempts by cities to improve solid waste management focused on the different technical means of collection and disposal (Altaf \& Deshazo 1996; Medina 2002). Collection and disposal of waste has always been the responsibility of government authorities in the past (Harris, Allison \& Smith, 2001), hence, waste management is a service for which state and local government is responsible (Cointreaus-Livine, 1994, Alabi, 2004). The inability of the government to manage solid waste collection and disposal effectively arose perhaps from the misconception of this task as a public good. Irrespective of the fact that government gave waste collection a priority in their development objectives, their ability to curtail the problems of waste collection deteriorates with time especially in the rural areas or emerging town like Nsukka, due to rising capital costs for plant and equipment, increasing operation and maintenance costs because of the rapid population growth of emerging urban areas with decreasing waste management coverage levels, and with increase in level of waste generated, confronted by increasing public demand for improved services and infrastructure (Salifu, 2001 and Sule, 1981), the need arises for the involvement of the private sector and the civil society in the provision of municipal solids waste service.

It should be noted, however, that it is only in the large urban centres of Nigeria such as Lagos, Ibadan, Warri, Suleja amongst others that the activities of formal private sector are recorded (Alabi, 2004). In majority of the cities such as Osogbo, they are neither totally absent or being substituted with the informal refuse collectors such as cart pushers. This therefore gives rise to the need to evaluate the household willingness to pay for improved solid waste disposal services in the study area. This study examined the general features of the existing waste management, household willingness potential to pay for improved waste disposal. The objective of this study is to examine household's preferences and willingness to pay for waste management services. Specifically, the study is designed to examine the extent cultural demographic and economic factors impact on household's preferences and willingness to pay for waste management services in Nsukka urban.

2. Literature Review

As argued by Tchobanglous (1993), all wastes emating from human and animal activities that are normally solid and are discarded as useless or unwanted are broadly defined as solid waste. It includes municipal garbage, industrial and commercial wastes, sewerage slug, waste of agricultural and animal husbandry, demolition waste and mining residues. Different individuals have defined solid waste differently. It encompasses household refuse, institutional wastes, street sweepings, commercial wastes, as well as construction and demolition debris. To Cointreau (1982), solid waste is material for which the primary generator or user abandoning the material within the urban area requires no compensation after abandonment. Solid Waste Management (SWM) is defined as the control, generation, storage, collection, transfer and transport, processing and disposal of solid waste consistent with the best practices of public health, economics \& financial, engineering, administrative, legal and environmental considerations (Othman, 2002). Solid waste management has three main components: collection and transportation; 
reuse or recycling; and treatment or disposal (SIDA, 2006). US EPA recommends using integrated, hierarchical approach to waste management with four components: source reduction, recycling, combustion, and land filling, to address the increasing volume of municipal solid waste. It ranks source reduction including reuse as the most preferred method, followed by recycling and composting, and lastly, disposal in combustion facilities and landfills.

Enger and Smith (2006) categorized solid waste in to four broader kinds as mining, agricultural, industrial, and municipal solid waste. Materials no longer used but are disposed because they are broke, spoiled, or have no longer uses are regarded as solid waste. Such waste can emanate households, commercial establishments, institutions, and some industries. Considering the points through which waste emanated, waste can be divided into: domestic waste, commercial waste, industrial waste, institutional waste, street sweepings and constructions waste. According to Cornwell (1998) solid waste can be classified as organic, inorganic, combustible, putrescible and non-putrescible factions. Cointreau (1982), Blight \& Mbande (1996), Arlosoroff (1982) notes that developing countries wastes are 2-3 times greater in waste density at the same time 2-3 times greater in moisture content than that of industrialized nations. Developing country wastes also involve large amount of organic waste (vegetable matter, etc.), large quantities of dust, dirt (street sweepings, etc), and smaller particle size on average than in industrialized nations. Although there might be some potential opportunities which arise from their waste composition, these peculiarities from industrialized nations present additional problems (Cointreau, 1982; Zerbock, 2003). Firstly, a higher solid waste density has many implications for the 'traditional' methods of collection and disposal.

Several empirical studies on waste management indicate that age, household size, sex, marital status, education and household are among factors affecting willingness to pay for effective waste management. Niringiye \& Omor (2010) found that age of the respondents has a negative and significant effect on waste management in Kampala city in Uganda. According to Yusuf, Salimonu \& Ojo(2007) on willingness to pay to improved household solid waste management in Oyo State, Nigeria. The outcome of the work showed that the maximum individual is willing to pay for improved solid waste management is N1240. Furthermore, it was discovered that other factors such as age, educational level, household size and households monthly expenditure and income affects willingness to pay for waste disposal.

Das \& Gogoi (2010) while analyzing the effect of in a municipal solid waste management of Tinsukia Municipality of Assam in India, observed that Cost of waste management is affected by family income positively. The result of the study shows that an increase in household income increases willingness to pay by as much as $13 \%$. Additionally, they found out that willingness and preference to pay for waste disposal also depend on the proportion waste the household generate per month. Household with huge waste to dispose have $21 \%$ willingness to pay for such services. Siriwardena \& Gunaratne (2007) and Jamal (2002), Pek et al., (2008) used the choice experiment and the multinomial logit regression to investigate solid waste management in Malaysia. Their findings were that the level of increase in waste disposal required better quality disposal options. They concluded that sanitary landfill is more preferred in solid waste disposal by the residents. The study of Morrison et al. (2002) on willingness to pay for waste disposal and management showed that, the willingness to pay by the respondents was negative. The respondents believe that the government should take care of the environmental issues. The implicit price obtained revealed that the households were not interested in environment improvement because there is an alternative to dispose wastes.

In his investigation of household preferences for solid waste management in Malaysia, Jamal (2002) that households derive positive utility from the provisions of compulsory recycling facilities for efficient waste disposal. Birol et al., (2009) estimated the value of improved wastewater treatment, a case study of river Ganga, in India by using the conditional logistic model. It was discovered that the coefficients were significant and in accordance to expectation. Treated wastewater quantity and quality were significant factors in the choice of a wastewater treatment programme. These two attributes increase the probability that a wastewater treatment programme is selected. In other words, households value those wastewater treatment programmes that result in higher quality and quantity of wastewater treated. While considering the attributes of frequency of vat collection, covered vats, covered collection trucks and monthly increase in tax, Sukanya et al., (2008) used the conditional logistic model and the random parameter model to estimate willingness made by the respondents to improvement in solid waste disposal. Their findings were that the poor and the rich have different attribute to payment. Whereas richer households were willing to pay more for higher wastewater treated to a quality, poorer households were rather willing to pay more for higher quantity of wastewater treated.

3. Methodolgy

The study adopted simple random sampling technique where 25 households were sampled from each of the six towns that make up Nsukka urban, giving a total sample of one hundred and fifty (150) respondents. The study made use of a structured questionnaire to collect data from respondents. The questionnaire supplied information on the factors that influence household willingness and preference for waste management service by households. It also 
elicited information concerning the cultural and demographic and economic factors influencing households' preferences and willingness to pay for waste management services. The descriptive statistics technique is adopted to show the characteristics of households' preferences and willingness to pay for waste management services. In furtherance, the probit regression analysis is employed to empirically estimate the impact of cultural and demographic and economic factors influencing household preferences and willingness to pay for waste management services.

\subsection{Model}

The probit regression model is used to estimate the impact of cultural and demographic and economic factors influencing household preferences and willingness to pay for waste management services in Nsukka Urban.. According to Wooldridge (2016), the linear probability model is suitable to model a dependent variable that takes values which are either 0 or 1 . Here, the probability of observing a 0 or 1 in any one case is treated as depending on one or more explanatory variables. Hence, for a binary outcome $Y$ and its associated vector of explanatory variables $X$, it is true that $P(Y=1 \mid X)=E(Y \mid X)$ i.e., the probability of success. This means that the probability that $Y=1_{y}$ given $X$ is the same as the expected value of $Y$ given $X$. This yields the probability equation: $P(Y=1 \mid X)=\alpha_{0}+\alpha_{1} x_{1}+\alpha_{2} x_{2} \ldots+\alpha_{k} x_{k}$ (1)

This indicates that the probability of success i.e., $P(Y=1 \mid X)$ is a linear function of $x_{i}$ variables. This equation is a typical instance of a linear probability model (LPM) because the response probability is linear in the parameters $\alpha_{i}$. In this model $\alpha_{i}$ measures the change in the probability of success when $x_{i}$ changes, holding other factors constant; expressed mathematically as

$$
\Delta P(Y=1 \mid X)=\alpha_{i} \Delta x_{i}(2)
$$

Of importance to note is that the $\alpha_{i}$ i.e., the vector of parameters of the linear probability model can be estimated with the ordinary least square method. In other words, this model is simple not just to estimate but to interpret, but it has some drawbacks (Wooldridge, 2016). The two most crucial demerits are: First, the fitted probabilities can be less than zero or greater than one i.e., that it can lie outside the 0-1 range. Second, the partial effect of any explanatory variable is constant. Put differently, it assumes that $P(Y=1 \mid X)$ increases linearly with $x_{i}$ variables. This assumption seem unrealistic because in reality, one would expect a nonlinear relationship between $P(Y=1 \mid X)$ and $x_{\tilde{i}}$. In other words, we need a more sophisticated binary response model i.e., a logistic regression model. In the LPM, the probability of success is given as $P(Y=1 \mid X)$ i.e., $P_{i}=E\left(Y_{i}=1 \mid X_{i}\right)$ as in Gujarati \& Porter (2009), but for logistic representation, the probability of success is given as:

$$
P_{i}=\frac{1}{1+e^{-\left(\alpha_{1}+\kappa_{2} x_{i}\right)}}
$$

$$
\text { If } Z_{i}=\alpha_{1}+\alpha_{2} X_{i}
$$

Equation 3 can be written as;

$P_{i}=\frac{1}{1+e^{-z_{i}}}=\frac{1}{1+\frac{1}{e^{z_{i}^{i}}}}$

With the lowest common multiple $=e^{z_{i}}$, the denominator of equation 5 can be deduced as: $\frac{1}{1}+\frac{1}{e^{z_{i}}}=\frac{e^{z^{i}}+1}{e^{z^{i}}}(6)$

If the denominator of equation (5) is replaced with (6) and in respect to cross multiplication rule, the $P_{\tilde{i}}$ solves down to: 
$\frac{1}{e^{z^{i}}+1} * e^{z_{i}}=\frac{e^{z_{i}}}{e^{z_{i}}+1}=\frac{e^{z_{i}}}{1+e^{z_{i}}}(7)$

Equation 7 is referred to as the logistic distribution function. From equation (7), it is easy to prove that as $Z_{\bar{i}}$ ranges from negative to positive infinity, $P_{\tilde{i}}$ ranges between 0 and 1 , and $P_{\tilde{i}}$ is nonlinearly related to $Z_{i}$ (i.e., $X_{i}$ ). This satisfies the two conditions considered earlier, but an estimation problem has been created because $P_{\tilde{i}}$ is nonlinear both in $X^{\prime} s$ and $\alpha^{\prime} s$ as can be seen from equation 3. This implies that the ordinary least square method cannot be used to estimate the parameters.

If the probability of success (i.e., the probability that the outcome of interest happens) is

$P_{i}=\frac{e^{z_{i}}}{1+e^{z_{i}}}$ as in equation (7), then the probability of failure is

$$
1-P_{i}=1-\frac{e^{z_{i}}}{1+e^{z_{i}}}=\frac{1}{1}-\frac{e^{z_{i}}}{1+e^{z_{i}}}
$$

Let LCM be $1+e^{z_{\tilde{i}}}$, so that equation 8 becomes:

$\frac{1+e^{z_{\tilde{i}}}-e^{z_{\hat{i}}}}{1+e^{z_{i}}}=\frac{1}{1+e^{z_{i}}}$

The odds ratio using equation 7 and 9 can therefore be written as:

$\frac{P_{i}}{1-P_{i}}=\frac{e^{z_{i}}}{1+e^{z_{i}}} * \frac{1+e^{z_{i}}}{1}=e^{z_{i}}(10)$

Equation (10) denotes the odds ratio in favour of success i.e., the ratio of the probability that an event of interest happens to the probability that it does not happen. Taking the natural log of equation 10 gives the following logit regression model

$L_{i}=\ln \left(\frac{P_{i}}{1-P_{i}}\right)=Z_{i}=\beta_{1}+\beta_{2} X_{i}(11)$

Accounting for the error term produces the following stochastic model

$L_{i}=\ln \left(\frac{P_{i}}{1-P_{i}}\right)=Z_{i}=\beta_{1}+\beta_{2} X_{i}+\mu_{i}(12)$

Pohlman \& Leitner (2003) compare the result of OLS with that of Logit for a binary dependent variable and concluded that probability model like Logit and Probit yield a better result than OLS. Secondly, almost all the review empirical studies on household willingness to pay for waste management employed probability modelling like probit to estimate the relationship. As such this research will follow the part of previous researchers like Das and Gogoi (2010); Siriwardena\&Gunaratne(2007); Jamal (2002), and Pek et al.,(2008) to estimate the household preference and willingness to pay for waste management service.

The observed binary $(1,0)$ for whether or not household has demanded for waste management service is expressed in the following probit regression model:

$\mathrm{Y}=\mathrm{bX} \mathrm{X}_{\mathrm{ij}}+\mathrm{e}_{\mathrm{ij}}$ 
where $Y=$ demand for waste management services $(1=$ Yes; $0=N o), X_{i j}=$ vector of explanatory variables, $b_{i j}=$ vector of parameter estimates

Model 1: Impact of cultural and demographic factors on preference and willingness to pay for waste management services

$$
\begin{gathered}
Y=f\left(X_{1}, X_{2}, X_{3}, X_{4}, X_{5}\right) \\
Y=b_{0}+b_{1} X_{1}+b_{2} X_{2}+b_{3} X_{3}+b_{4} X_{4}+b_{5} X_{5}+u
\end{gathered}
$$

$\mathrm{Y}=$ demand for waste management services $(1=\mathrm{Yes} ; 0=\mathrm{No}), \mathrm{X}_{1}=$ Age (in years), $\mathrm{X}_{2}=$ Gender $(1=$ Female; $0=$ Male), $\mathrm{X}_{3}=$ marital status $\left(1=\right.$ married; $0=$ unmarried), $X_{4}=$ education (number of years in school for the head of the family), $\mathrm{X}_{5}=$ family size (in person), $\mathrm{b}_{1-5}=$ coefficient of explanatory variables, $\mathrm{u}=$ Error term.

\section{Model 2: Impact of economic factors on preference and willingness to pay for waste management services}

$$
\begin{gathered}
Y=f\left(X_{1}, X_{2}, X_{3}\right) \\
Y=b_{0}+b_{1} X_{1}+b_{2} X_{2}+b_{3} X_{3}+u
\end{gathered}
$$

$\mathrm{Y}=$ demand for waste management services $(1=\mathrm{Yes} ; 0=\mathrm{No}), \mathrm{X}_{1}=$ cost of waste management service $(1=\mathrm{Affordable}$; $0=$ Not affordable), $X_{2}=$ household monthly income $(N), X_{3}=$ house ownership (1= Owner of house; $0=$ Non-owner of house), $\mathrm{X}_{4}=$ awareness about environmental implication of waste management service $(1=\mathrm{Yes} ; 0=\mathrm{No}), \mathrm{b}_{1-4}=$

\begin{tabular}{|c|c|c|}
\hline & Frequency & Percentage \\
\hline \multicolumn{3}{|c|}{ Demand for Waste Management services } \\
\hline Yes & 123 & $82.0 \%$ \\
\hline No & 27 & $18.0 \%$ \\
\hline Total & 150 & $100.0 \%$ \\
\hline \multicolumn{3}{|l|}{ Age (in years) } \\
\hline $20-29$ years & 12 & $8.0 \%$ \\
\hline 30-39years & 28 & $18.7 \%$ \\
\hline 40-49years & 38 & $25.3 \%$ \\
\hline 50-59years & 43 & $28.7 \%$ \\
\hline Above 60 years & 29 & $19.3 \%$ \\
\hline Total & 150 & $100.0 \%$ \\
\hline \multicolumn{3}{|l|}{ Gender } \\
\hline Female & 102 & $64.0 \%$ \\
\hline Male & 48 & $32.0 \%$ \\
\hline Total & 150 & $100.0 \%$ \\
\hline \multicolumn{3}{|c|}{ Occupational Status } \\
\hline Employed & 132 & $88.0 \%$ \\
\hline Unemployed & 18 & $12.0 \%$ \\
\hline Total & 150 & $100.0 \%$ \\
\hline \multicolumn{3}{|l|}{ Family Size } \\
\hline 1-3persons & 33 & $22.0 \%$ \\
\hline 4-6persons & 88 & $58.7 \%$ \\
\hline Above 6 persons & 29 & $19.3 \%$ \\
\hline Total & 150 & $100.0 \%$ \\
\hline
\end{tabular}
coefficient of explanatory variables, $\mathrm{u}=$ error term.

4. Results and Discussion

Table1: Socioeconomic and demographic distribution of respondents 
Table 2: Economic factors influencing Household willingness to pay for Waste Management Services

\begin{tabular}{|c|c|c|}
\hline & Frequency & Percentage \\
\hline \multicolumn{3}{|c|}{ Cost of Waste management Services } \\
\hline Affordable & 140 & $93.3 \%$ \\
\hline Not affordable & 10 & $6.7 \%$ \\
\hline Total & 150 & $\mathbf{1 0 0 . 0 \%}$ \\
\hline \multicolumn{3}{|c|}{ Household Monthly Income } \\
\hline None & 0 & 0 \\
\hline Below N100, 000 & 105 & $70.0 \%$ \\
\hline $\mathrm{N} 100,000-\mathrm{N} 200,000$ & 34 & $22.7 \%$ \\
\hline Above N200, 000 & 11 & $7.3 \%$ \\
\hline Total & 150 & $100.0 \%$ \\
\hline \multicolumn{3}{|l|}{ Ownership Status } \\
\hline Owner & 95 & $63.3 \%$ \\
\hline Rented & 55 & $36.7 \%$ \\
\hline Total & 150 & $100.0 \%$ \\
\hline \multicolumn{3}{|c|}{ Awareness about Environmental Information } \\
\hline Yes & 130 & $86.7 \%$ \\
\hline No & 20 & $13.3 \%$ \\
\hline Total & 150 & $100.0 \%$ \\
\hline
\end{tabular}

Source: Authors computation from field survey data

In Table 1, it was revealed that $82 \%$ of the respondents are willing to pay for waste management services, $18 \%$ did not prefer and neither willing to pay for waste management services in Nsukka urban. Based on age distribution, $12(8 \%)$ of the respondents are between 20-29years; $28(18.7 \%)$ are between $30-39$ years; 38(25.3\%) are between 4049 years; $43(28.7 \%)$ are between 50-59 years and 29(19.3\%) are above 60 years. Based on gender distribution, $102(68 \%)$ of the respondents, which constituted the majority are female while the remaining 48(32\%) are male. Based on occupational status, 132(88\%) of the respondents, which formed the majority are employed while the remaining 18(12\%) are unemployed. Based on family size, 33(22\%) of the respondents have a household size between 1-3persons; 88(58.7\%) have between 4-6persons and 29(19.3\%) have above 6 person in their family. On the economic factors affecting household preference and willingness to pay for waste management services, it was revealed that $140(93.3 \%)$, which is the majority, reported that the cost of waste management services is affordable while the remaining $10(6.7 \%)$ stated that it is unaffordable. Based on monthly income distribution, 105(70\%) of the respondents earn below N100, 000; 34(22.7\%) earn between N100, 000- N200, 000 and 11(7.3\%) earn above N200, 000. Based on ownership status, 95(63.3\%) of the respondents are the owner of the house while the remaining $55(36.7 \%)$ are leaving in rented apartment

Table 3: Probit regression result on the impact of cultural and demographic factors on Household willingness to pay for waste management services

\begin{tabular}{crrrrr}
\hline Variable & Coefficient & Std. Error & z-Statistic & Prob. & Remark \\
\hline \hline C & & & & & Significant \\
\hline AGE & -4.0796 & 1.2345 & -3.3041 & 0.0010 & Significant \\
\hline GENDER & -0.0719 & 0.0210 & -3.4197 & 0.0006 & Non- Significant \\
\hline MARITAL & 0.5697 & 0.3767 & 1.5149 & 0.1298 & Non \\
\hline EDUCATION & -0.2201 & 0.6214 & -0.3542 & 0.7232 & Non- Significant \\
\hline SIZE & 0.1515 & 0.0658 & 10.7833 & 0.0000 & Significant \\
\hline
\end{tabular}




\begin{tabular}{lrlr}
\hline McFadden R-squared & 0.5881 & Mean dependent var & 0.8200 \\
\hline LR statistic & 83.1726 & Avg. log likelihood & -0.1942 \\
\hline Prob(LR statistic) & 0.0000 & & \\
\hline \hline
\end{tabular}

Source: Authors computation from field survey data

The result in Table 3 shows that age, education and family size are the significant cultural and demographic factors that affects the demand for waste management while marital status and gender does not have strong influence in determining household willingness and preference for waste management service. Also, as family size becomes larger, the probability of such family to demand for waste management services will increase because the family will tend to generate more waste over time. In furtherance, being educated increases the probability of demanding for waste management services as they can afford the inherent cost and are aware of the health implication of poor waste management. Being married increases the likelihood of demanding for waste management services since more waste will be generated over time and similarly female head of the family tends to increase the probability demanding for waste management service than the family with male head since the male head is not involved in the waste disposal. The findings its an indication that demographic factors combine plays significant role in household waste management service preference and willingness to pay.

Table 4: Probit regression result on the impact of economic factors on household willingness to pay for waste management

\begin{tabular}{cccccr}
\hline \hline Variable & Coefficient & Std. Error & z-Statistic & Prob. & Remarks \\
\hline \hline C & & & & & \\
\hline COST & -3.3799 & 0.8690 & -3.8894 & 0.0001 & Significant \\
\hline INCOME & 2.7935 & 0.6188 & 4.5167 & 0.0000 & Significant \\
\hline OWNERSHIP & $1.27 \mathrm{E}-05$ & $4.59 \mathrm{E}-06$ & 2.7718 & 0.0056 & Significant \\
\hline AWARENESS & 0.0154 & 0.2983 & 0.0514 & 0.9590 & Not-Significant \\
\hline \hline McFadden R-squared & 1.0424 & 0.3855 & 2.7048 & 0.0068 & Significant \\
\hline LR statistic & 0.6214 & Mean dependent var & 0.8200 & \\
\hline Prob(LR statistic) & 45.4458 & Avg. log likelihood & -0.3197 & \\
\hline \hline
\end{tabular}

Source: Authors computation from field survey data

The results in Table 4 depicts that cost of waste management in terms of affordability, household average monthly income and awareness of the environmental factor of waste management are the significant economic determinants of demand for waste management services while ownership of the property, whether the household own the house they live or not does not play any significant role in household preference and willingness to pay for waste management services. Cost of waste management, household income, environmental awareness and ownership positively impacts on demand for waste management. For example, if people can afford the cost of waste management services, the probability of them demanding for such services will increase. Also, as individual's income rises, chances are that there will be an increase in the demand for waste management services. Being aware of the environmental consequences of improper waste management or being aware of waste management service will increases the likelihood of demanding for waste management services and owners of house tends to increase the willingness of the household preference and willingness to pay for waste management services.

5. Conclusion

This study has made considerable effort to examine household willingness and preferences to pay for waste management services. From the analysis, it is evident that household head age, family size and level of education of the household head plays significant role in their preference and willingness to pay for waste management services. Beside, cost of waste management service in terms of affordability, household income and awareness influences household preference and willingness to pay for waste management services. Arising from these findings, government should subsidies the price of waste management service to encourage more households to demand for waste management services. 


\section{References}

Boniface, O W (2016). Municipal solid waste characterization in Nsukka urban in South East Nigeria, Transylvanian Special Issue Review, XXIV, (7)

Adinnu, I. F (1994). Landfill and urban residential rental values: A case Study of Achapo landfill facility in OjoLGA, Lagos State, Unpublished MURP Dissertation. Centre for Urban and Regional Planning, University of Ibadan.

Agbola, T. (2001). Turning Municipal waste into compost: The case of Ibadan. In: Drechsel, P. and D. Kunze (eds), Waste composting for urban and Peri- urban agriculture closing the rural-urban. nutrient cycle in SubSaharan Africa, International Waste Management Institute, Food and Agriculture Organization of the United Nation, CABI publishing, OXon, UK,. 69-81.

Alabi, M (2004). Waste products survey for identification and quantification of different wastes generated in Nigeria. An Unpublished PhD Thesis in the Dept of Geography, University of Ibadan

Centre for African Settlement Studies and Development (CASSAD) (1998). Workshop on turning waste to wealthstrategies, options, appropriate and affordable technology for waste management, Training Module Prepared Course Codes CASTWW/98 April

Cointreaus-Levine, S. (1994). Private sector participation in Municipal solid waste services in developing countries, 1, The Formal Sector. Published for Urban. Management Programme by the World Bank, Washington, D.C.

Harris, P J., C, M. Allison, G. Smith, H. M. Kindness \& Kelley, J. (2001). The potential use of waste-stream products for soil amelioration in Peri-urban interface Agricultural production systems'. In: Drechsel, P \& D. Kunze (eds), op.cit., 1-28

Salifu, L (2001). An integrated waste management strategy for Kumasi, In: Drechsel, P \& D Kunze (eds), op.cit., $112-114$

Sule, R A O (1981). The deterioration of the Nigerian environment solid waste disposal in Metropolitan Lagos, Geojournal, 3, 57-77

Yusuf, S., A, Ojo, OT \& KK (2007). Households' willingness to pay for improved household solid waste management in Ibadan-North LGA of Oyo State, Nigeria Journal of Environmental Extension, 6, 57-63

Arrow, J.K., R. Solow, P.R. Portney, E.E. Leamer, R. Radner \& Schumand, H. (1993). Report of the NOAA panel on contingent valuation, Federal Register, 58 (10), 4601-4614

Bartone, C.L \& Bernstein. J. D 1993. Improving Municipal solid waste management in Third World Countries, Resources, Conservation \& Recycling, 8, 43-45

Cameron, T.A \& James. D. M (1987). Efficient estimation methods for use with closed-ended contingent valuation surveys data, Review of Economics and Statistics, 69. 269-276

Carson, R.T. 2002. Contingent valuation: A comprehensive bibliography and history. Cheltenham, UK: Edward Edgar

Carson R.T., N. Flores \& Meade, N. 2001. Contingent valuation: Controversies and evidence, Environmental \& Resource Economics, 19 (2), 173-210

Carson, R.T., W.M. Hanemann, R.J. Kopp, J.A. Krosnick, R.C. Mitchell, S. Presser, P.A. Ruud, V. Keny Smith, M. Conaway \& Martin, K. (1998). Referendum design and contingent valuation: The NOAA panel's no-vote recommendation, Review of Economics \& Statistics, 80 (2), 335-338

Chakrabarti, S \& Sarkhel, P. (2003). Economics of solid waste management: A survey of existing literature, Kolkata, India: Indian Statistical Institute, Economic Research Unit

Chuen-Khee, P \& Othman, J (2010). Household demand for solid waste disposal options in Malaysia, World Academy of Science, Engineering \& Technology, 66, 1153-1158

Fantu, S. (2007). Household heads' willingness to pay for improved solid waste management: The case of common building residences in Addis Ababa, MA thesis, Department of Economics, Addis Ababa, Ethiopia

\section{Copyrights}

Copyright for this article is retained by the author(s), with first publication rights granted to the journal.

This is an open-access article distributed under the terms and conditions of the Creative Commons Attribution license (http://creativecommons.org/licenses/by/4.0/) 